\title{
Upregulation of allograft inflammatory factor-1 expression and secretion by macrophages stimulated with aldosterone promotes renal fibroblasts to a profibrotic phenotype
}

\author{
YUSHU LI, XINGZHI WANG, LEI ZHANG, XUEYING YUAN, JIANBING HAO, JIE NI and LIRONG HAO
}

Department of Nephropathy, First Affiliated Hospital of Harbin Medical University, Harbin, Heilongjiang 150001, P.R. China

Received November 18, 2017; Accepted May 4, 2018

DOI: 10.3892/ijmm.2018.3667

\begin{abstract}
Macrophages have been identified as a key cell type in the pathogenesis of renal interstitial fibrosis (RIF). However, the mechanism through which macrophages drive fibrosis remains unclear. The current study focuses on the effects and possible underlying mechanism of allograft inflammatory factor-1 (AIF-1), an inflammation-responsive scaffold protein expressed and secreted by macrophages, in promoting fibroblasts to a profibrotic phenotype. In vivo experiments indicated that AIF-1, CD68 and $\alpha$-smooth muscle actin ( $\alpha$-SMA) were upregulated in kidney tissues of mice subjected to unilateral ureteric obstruction, while their expressions were inhibited by an aldosterone receptor antagonist, spironolactone. Double immunofluorescence staining revealed that AIF-1 expression co-localized with CD68-positive macrophages in the renal interstitium, indicating that AIF-1 expression in macrophages was increased in the RIF animal model. Furthermore, to identify the role of AIF-1 in promoting fibrosis, its expression and secretion by the RAW264.7 macrophage cell line were detected in vitro. The expression levels of $\alpha$-SMA, phosphorylated p38 (p-p38) and fibronectin (FN) in fibroblasts were examined subsequent to co-culture with macrophages. The increase in AIF-1 expression and secretion was confirmed in RAW264.7 cells in response to aldosterone. After $72 \mathrm{~h}$ of co-culture between fibroblasts and macrophages stimulated with aldosterone, the $\alpha$-SMA expression was induced in fibroblasts, with significantly increased expression levels of FN and p-p38 observed. In addition, AIF-1 expression was reduced by stable transfection of RAW264.7 cells with AIF-1 small interfering RNA, resulting in significantly reduced expression levels of $\alpha$-SMA, p-p38 and FN in fibroblasts co-cultured with macrophages as compared with normal macrophages. These
\end{abstract}

Correspondence to: Dr Lirong Hao, Department of Nephropathy, First Affiliated Hospital of Harbin Medical University, 23 Youzheng Street, Nangang, Harbin, Heilongjiang 150001, P.R. China E-mail: hao_lirong@163.com

Key words: allograft inflammatory factor-1, macrophage, p38 mitogen-activated protein kinase, renal fibroblast, renal interstitial fibrosis findings indicate that the expression of AIF-1 in macrophages is critical for the activation of renal fibroblasts to a profibrotic phenotype. AIF-1 expression was upregulated in macrophages, and may be a novel mechanism linking macrophages to the promotion of RIF via the $\mathrm{p} 38$ signaling pathway.

\section{Introduction}

Renal interstitial fibrosis (RIF) is the main pathway leading to an irreversible loss of renal function, and has a poor prognosis requiring dialysis or transplantation. In addition to excessive deposition of extracellular matrix (ECM), RIF is also associated with leukocyte infiltration, myofibroblast accumulation and tubular atrophy (1). Fibrogenesis refers to the deposition of pathological matrix by cells, and is widely considered as a wound-healing response to tissue injury (2). The process is associated with inflammatory cell recruitment and the appearance of myofibroblasts, which serve a key role in ECM remodeling.

Myofibroblasts may serve a beneficial role in wound healing; however, myofibroblasts and inflammatory cells persist in the case that the injury does not abate, resulting in the loss of the reparative and healing processes (3). Previous studies $(4,5)$ investigating forkhead box D1 lineage cells have reported that resident fibroblasts are one of the major precursors of myofibroblasts, whereas other studies have concluded that resident fibroblasts are equivalent to myofibroblasts cells in the kidney. It is known that renal fibroblasts migrate, proliferate and then proceed to differentiate into myofibroblasts, expressing $\alpha$-smooth muscle actin ( $\alpha$-SMA) $(6,7)$.

The recruitment of inflammatory cells to the injury tissue also serves a pivotal role in wound-healing responses. Occurrence of RIF is reported when kidney repair is insufficient or consistently suppressed by ongoing tissue injury and inflammation (7). As a member of the mononuclear phagocyte family, macrophages function as a key player in renal injury, inflammation and fibrosis. In addition, macrophages are pleiotropic inflammatory cells that participate in inflammatory reactions (8). With recruitment to the inflammatory milieu, macrophages interact with other cell types, such as fibroblasts, which transdifferentiate into matrix-secreting myofibroblasts, resulting in scar formation and structure destruction (9). The importance of macrophages in renal inflammation and fibrosis responses has been reported in clinical and experimental 
studies. Tubulointerstitial macrophage infiltration in renal biopsies from patients is correlated with the severity of interstitial fibrosis and progression of chronic renal failure to end-stage renal failure (10). Experimental hydronephrosis induced by unilateral ureteric obstruction (UUO) is frequently used as a reliable model to investigate $\operatorname{RIF}$ in mice $(11,12)$. This model is characterized by infiltrating tubulointerstitial macrophages, and RIF occurs rapidly over the course of 5 days (13). Furthermore, the inhibition of macrophage recruitment and interstitial infiltration reduces the severity of renal fibrosis, demonstrating that macrophages serve a pivotal role in promoting RIF subsequent to UUO (14-16). Macrophages generate several profibrotic factors, including galectin-3 (17,18), transforming growth factor (TGF)- $\beta$ (19), insulin-like growth factor-1 (20), platelet-derived growth factor $(21,22)$ and basic fibroblast growth factor $(23)$, which support the generation, survival and proliferation of myofibroblasts, and drive tissue fibrosis. Therefore, increasing our understanding on the mechanisms of macrophages in progressive renal fibrosis is a critical step toward the design of novel diagnostic and therapeutic targets.

Allograft inflammatory factor-1 (AIF-1) is a $17-\mathrm{kDa}$ cytoplasmic, calcium-binding, inflammation-responsive scaffold protein that is mainly expressed in immunocytes (24). AIF-1 mRNA was cloned from activated macrophages in rat and human cardiac allografts with chronic rejection $(25,26)$. In addition, three other proteins appear to be identical to AIF-1, including ionized $\mathrm{Ca}^{2+}$-binding adapter molecule-1 (27), microglia response factor-1 (28) and daintain (29). AIF-1 is expressed in macrophages and upregulated in active macrophages, and its expression is associated with inflammatory actions (30). Furthermore, AIF-1 promotes macrophage proliferation, migration and the expression of inflammatory mediators, such as cytokines and chemokines, which in turn inhibits macrophage apoptosis (30-33). Given that AIF-1 is crucial for the survival and proinflammatory activity of macrophages, subsequent studies have indicated that numerous pathological processes are regulated by AIF-1 in macrophages, including allograft rejection, autoimmune diseases and vasculopathy $(24,34)$. The correlation between AIF-1, as a marker of active macrophages, and kidney disease has also been receiving increasing attention. Subsequent to investigating the correlation between serum AIF-1 concentrations and diabetic nephropathy, a previous study has identified that serum AIF-1 concentration was correlated with albuminuria and the estimated glomerular filtration rate in patients with type 2 diabetes, and suggested that it may serve as a marker of diabetic nephropathy as well as activated macrophages (35). Meanwhile, AIF-1 can be detected in the liver tissue of mice infected with Schistosoma japonicum and may alleviate hepatic fibrosis at the middle to advanced stages of infection (36). Furthermore, AIF-1 participates in the early pathogenesis of systemic sclerosis by the production of cytokines capable of promoting fibroblasts to a fibrotic phenotype (37), which demonstrates that AIF-1 may be involved in the promotion of fibrosis.

Aldosterone, as a steroid hormone regulating sodium and potassium homeostasis, causes inflammation, tubulointerstitial fibrosis and glomerular injury in the kidney. Based on these findings, aldosterone increases the expression of a number of profibrotic molecules that participated in aldosterone-induced fibrosis (38). In the present study, it was hypothesized that AIF-1 expressed by macrophages drives the progression of RIF in a UUO animal model. Furthermore, using a co-culture of macrophages induced by aldosterone and fibroblasts, it was examined in vitro whether AIF-1 upregulated in macrophages promotes fibroblasts to a profibrotic phenotype and induces RIF.

\section{Materials and methods}

Animals. A total of 45 male C57BL/6 mice (6-week-old) were purchased from Charles River Laboratories, Inc. (Beijing, China). The mice were kept at a conventional temperature $\left(23 \pm 2^{\circ} \mathrm{C}\right)$ and a humidity of $50 \%$ with a $12 \mathrm{~h}$ light/dark cycle. Mice had ad libitum access to food and water. The mice were divided into three groups (15 in each group) after 7 days of acclimatization, including the experimental, spironolactone (SPI) and control groups. In the experimental group, UUO was performed by complete ligation of the left ureter as described previously (39) and saline was administered by gavage. In the SPI group, UUO mice were administered SPI (Sigma-Aldrich; Merck KGaA, Darmstadt, Germany) by gavage (20 mg/kg/day) $24 \mathrm{~h}$ after UUO. Mice in the control group underwent sham surgery in the ureter, which was dissociated with no ligation, and saline by gavage. Mice were anesthetized and kidneys were harvested at 14 days after UUO. Next, the kidney tissue was divided into three sections. One section was fixed in Carnoy solution (containing 60\% methanol, 30\% chloroform and $10 \%$ glacial acetic acid) and embedded in paraffin for immunohistochemical analysis. Another tissue section was perfused with optimum cutting temperature reagent (Sakura Finetek, Inc., Torrance, CA, USA) and immediately frozen in liquid nitrogen for use in immunofluorescence assay. The remainder of the sample was snap-frozen in liquid nitrogen for reverse transcription-quantitative polymerase chain reaction (RT-qPCR) analysis. All experimental procedures adhered to the principles stated in the Guide for the Care and Use of Laboratory Animals (updated 2011; National Institutes of Health, Bethesda, MD, USA) and were approved by the Experimental Animal Usage and Welfare Ethic Committee of Harbin Medical University (Harbin, China).

Immunohistochemical and immunofluorescence assays. Sections $(4 \mu \mathrm{m})$ of the paraffin-embedded kidney tissues were processed for immunohistochemistry. Serial sections were deparaffinized in xylene, rehydrated in an alcohol series and washed in phosphate-buffered saline (PBS)/Tween-20. All sections underwent antigen retrieval with hydrated autoclaving for $20 \mathrm{~min}$ in citrate solution, and then blocked with $3 \% \mathrm{H}_{2} \mathrm{O}_{2}$ in PBS for $10 \mathrm{~min}$ at room temperature. For blocking the antigen, $5 \%$ bovine serum albumin was used for $20 \mathrm{~min}$ at room temperature. Next, the slides were incubated overnight at $4^{\circ} \mathrm{C}$ with the following primary antibodies: Rabbit anti-mouse polyclonal AIF-1 (cat no. 10904-1-AP; 1:200 dilution; ProteinTech Group, Inc., Chicago, IL, USA), rabbit anti-mouse polyclonal CD68 (cat no. ab125212; 1:400 dilution; Abcam, Cambridge, UK) and goat anti-mouse polyclonal $\alpha$-SMA (cat no. orb18863; $1: 500$ dilution; Biorbyt Ltd., Cambridge, UK). All sections were then incubated with peroxidase-conjugated goat (cat no. SV0003) or rabbit (cat no. SV0002) IgG (ready-to-use; Boster Biological 
Technology, Ltd., Wuhan, China) as the secondary antibody for $30 \mathrm{~min}$ at room temperature. The immune complex was visualized with $\mathrm{DAB}$, serving as the chromogenic substrate, and subsequently counterstained with hematoxylin.

For immunofluorescence analysis, sections were incubated with primary antibodies against AIF-1 (cat no. ab5076; $0.5 \mu \mathrm{g} / \mathrm{ml}$ ) and CD68 (cat no. ab53444; $1.0 \mu \mathrm{g} / \mathrm{ml}$ ) (all from Abcam) for $1 \mathrm{~h}$ at room temperature, followed by a 30 -min incubation with secondary antibody conjugated to FITC (cat no. BA1110; 1:32 dilution) and biotinylated secondary antibody followed by SABC-Cy3 (cat no. SA1079; 1:100 dilution) in an immunohistochemistry Elite kit (Boster Biological Technology, Ltd.) at $37^{\circ} \mathrm{C}$ in the dark. Subsequent to washing with PBS, the samples were observed using a NIKON ECLIPSE 80i confocal fluorescence microscopy (Nikon Corporation, Tokyo, Japan).

Masson's trichrome stain. Serial sections were deparaffinized in xylene (10 min each, twice) and rehydrated in an alcohol series $(100,95$ and $70 \%)$ for 5 min each, twice at room temperature. All sections were washed in running water for 5 min and stained using a Masson's trichrome-staining kit (cat no. BA-4079B; Baso Diagnostics, Inc., Hubei, China) according to the manufacturer's protocol. The sections were treated as follows: All sections were stained with Weigert-iron-hematoxylin (1:1) for $5 \mathrm{~min}$ at room temperature. Following washing in running water for $10 \mathrm{~min}$, the sections were treated with hydrochloride-ethanol solution $(1 \%)$ for $5 \mathrm{sec}$ at room temperature and rinsed under running tap water for $20 \mathrm{~min}$. The sections were stained in ponceau (1\%) staining solution for 5-10 min at room temperature (observed under an electron microscope with a magnification of x200) and washed using phosphomolybdic acid solution (Baso Diagnostics, Inc.) for $5 \mathrm{~min}$ at room temperature. All sections were stained with aniline blue solution for $\sim 5 \mathrm{~min}$ at room temperature (observed under an electron microscope with a magnification of $\mathrm{x} 200$ ) and followed by washing in glacial acetic acid for $1 \mathrm{~min}$. Subsequent to dehydration through an ethanol series (95 and $100 \%, 10 \mathrm{~min}$ each, twice) and xylene (5 min each, twice), followed by all sections being cover slipped.

Cell culture and stable transfections. The mouse macrophage cell line RAW264.7 and renal fibroblast cell line BHK-21 were purchased from the American Type Culture Collection (Manassas, VA, USA). Cells were cultured in Dulbecco's modified Eagle's medium (DMEM) with $10 \%$ fetal bovine serum at $37^{\circ} \mathrm{C}$ in $5 \% \mathrm{CO}_{2}$ incubator. Equal numbers of RAW264.7 cells were seeded into $100-\mathrm{mm}$ culture dishes $\left(1 \times 10^{5}\right.$ per dish) for western blot analysis and 6-well plates $\left(1 \times 10^{6}\right.$ per well) for RT-qPCR. Confluent RAW264.7 cells were starved in serum-free DMEM for $24 \mathrm{~h}$ and then exposed to different concentrations of aldosterone $\left(10^{-8}-10^{-5} \mathrm{M}\right.$; Sigma-Aldrich; Merck KGaA) for $72 \mathrm{~h}$. Another part of cells was stimulated with $10^{-6} \mathrm{M}$ aldosterone for different incubation times $(6,24,72$ and $120 \mathrm{~h})$. Samples were subsequently processed for protein and RNA isolation and further detection.

For AIF-1 gene knockdown, a small interfering RNA (siRNA) construct was synthesized by GenePharma Co., Ltd. (Shanghai, China), and its sequence was as follows: 5'-GCAAUGGAGAUA UCGAUAUTTAUAUCGAUAUCCAUUGCTT-3'. The siRNA was inserted into the expression vector pRNA-U6.1/shuttle (pShuttle). RAW264.7 cells were transfected with the vector alone or with pRNAU6.1/shuttle-siRNA/AIF-1 with Lipofectamine ${ }^{\circledR}$ 2000 reagent (Invitrogen; Thermo Fisher Scientific, Inc., Waltham, MA, USA) as described previously (40). Following antibiotic selection (400 g/ml G418; Thermo Fisher Scientific, Inc.), stably transduced macrophages were pooled to avoid the effects of clonal selection. The expression levels of AIF-1 in macrophages subsequent to transfection were detected by western blot analysis and RT-qPCR.

Co-culture of macrophages with renal fibroblasts. Normal macrophages and macrophages transfected with siRNA/AIF-1 stimulated with aldosterone were co-cultured with renal fibroblasts. Prior to co-culture, RAW264.7 cells $\left(1 \times 10^{6}\right)$ were cultured in 6-well plates, while $1 \times 10^{6} \mathrm{BHK}-21$ were cultured in $100-\mathrm{mm}$ culture dishes, and cells were incubated in serum-free media for $24 \mathrm{~h}$. Following digestion by trypsin/EDTA and separation from the supernatant, the pellet of RAW264.7 cells $\left(1 \times 10^{7}\right)$ was resuspended and added to the BHK-21 culture. After aldosterone $\left(10^{-6} \mathrm{M}\right)$ was added, cells were incubated for a further $72 \mathrm{~h}$. Prior to the extraction of total RNA and protein from the fibroblasts for expression detection, macrophages were removed by rinsing extensively with PBS until a few macrophages could be detected microscopically. The expression levels of FN, $\alpha$-SMA, p38 and phosphorylated-p38 (p-p38) from BHK-21 cells and AIF-1 from RAW264.7 cells were examined.

$R T-q P C R$. Total RNA was extracted from the samples using TRIzol (Invitrogen; Thermo Fisher Scientific, Inc.) according to standard procedures. Next, the concentration of RNA $\left(\mathrm{C}_{\mathrm{RNA}}=950-1,500 \mathrm{ng} / \mu \mathrm{l}\right)$ samples were tested using a spectrophotometer (NanoDrop 2000; Thermo Fisher Scientific, Inc.). When the A260/A280 ratio was 1.8 to 2.0, it was deemed to have met the experimental requirements. The volumes of RNA $\left(\mathrm{V}_{\mathrm{RNA}}=1 \mu \mathrm{g} / \mathrm{C}_{\mathrm{RNA}}\right)$ for RT were calculated according to the concentrations of RNA. $1 \mu \mathrm{g}$ RNA was reverse-transcribed into cDNA (20- $\mu 1$ reactions), and qPCR was performed using SYBR Premix Ex Taq ${ }^{\mathrm{TM}}$ II (Takara Bio, Inc., Otsu, Japan) with LightCycler 2.0 instrument (Roche Diagnostics $\mathrm{GmbH}$, Mannheim, Germany). A total of $0.4 \mu \mathrm{M}$ of the following primers was used for qPCR: FN forward, 5'-CAAAGATGA CAAGGAAAGTGCC-3', and reverse, 5'-CCCGATAATGGT GGAAGAGT-3'; $\alpha$-SMA forward, 5'-GCATCCGACCTTGCT AACG-3', and reverse, 5'-CATCTCCAGAGTCCAGCACAA T-3'; p38 forward, 5'-ACCTAAAGCCCAGCAACCT-3', and reverse, 5'-CAGCCCACGGACCAAATA-3'; AIF-1 forward, 5'-GTTCCCAAGACCCATCTAGAGCTG-3', and reverse, 5'-AGTTGGCTTCTGGTGTTCTTTGTTT-3'; GAPDH forward, 5'-ACCACAGTCCATGCCATCAC-3', and reverse, 5'-TCCACCACCCTGTTGCTGTA-3'. GAPDH served as the endogenous reference gene. According to the manufacturer's protocol, the relative gene expression levels were presented with the $2^{-\Delta \Delta \mathrm{Ct}}$ method, defined as the comparative quantification cycle (41).

Western blotting. Cultured cells were lysed by adding lysis buffer (radioimmunoprecipitation assay to phenylmethane sulfonyl fluoride ratio, 99:1), and protein was extracted in 1X SDS sample buffer following centrifugation at $12,000 \mathrm{x} \mathrm{g}$ for 
$15 \mathrm{~min}$ at $4^{\circ} \mathrm{C}$. The protein concentration of each sample was measured using a BCA protein assay kit (cat no. ab207002; Abcam). Equal amounts of protein were separated using SDS-PAGE (12\%), transferred onto polyvinylidene difluoride membranes, and then blocked in Tris-buffered saline/Tween-20 containing $5 \%$ non-fat milk for $1 \mathrm{~h}$ at room temperature. The membranes were incubated overnight at $4^{\circ} \mathrm{C}$ with the following primary antibodies: Rabbit anti-mouse polyclonal p38 (cat no. 8690S; 1:1,000 dilution), p-p38 (cat no. 4511S; 1:1,000 dilution) (both from Cell Signaling Technology, Inc.), FN (cat no. 15613-1-AP; 1:1,000 dilution; ProteinTech Group, Inc.) and GAPDH (cat no. 10494-1-AP; 1:5,000 dilution; ProteinTech Group, Inc.) antibodies; AIF-1 and $\alpha$-SMA antibodies were used as described earlier. Following incubation with horseradish peroxidase conjugated-secondary antibodies (cat no. ZB2301; 1:2,000 dilution; OriGene Technologies, Inc., Rockville, MD, USA) for $1 \mathrm{~h}$ at $37^{\circ} \mathrm{C}$, the membranes were treated with an enhanced chemiluminescence substrate kit to obtain visible bands, which were observed with a ImageQuant LAS-4000 device (GE Healthcare, Chicago, IL, USA).

Enzyme-linked immunosorbent assay (ELISA). The concentration of AIF-1 and TGF- $\beta$ in culture supernatants were determined using a mouse AIF-1 ELISA kit (cat no. 0000768; Tsz Biosciences, San Francisco, CA, USA) and TGF- $\beta$ ELISA kit (cat no. E-EL-M1192c; Elabscience Biotechnology Co., Ltd., Wuhan, China) according to the manufacturer's protocol. Briefly, the supernatants were obtained following centrifugation at $1,000 \times \mathrm{g}$ for $20 \mathrm{~min}$ at $4^{\circ} \mathrm{C}$. Standard solution $(4-500 \mathrm{pg} / \mathrm{ml})$ and supernatant samples $\left(1 \times 10^{4}\right)$ were added to the 96 well plates, and the plate was incubated at $37^{\circ} \mathrm{C}$ for $45 \mathrm{~min}$. Subsequent to washing with PBS with $10 \%$ Tween-20 (PBST), $50 \mu \mathrm{l}$ anti-biotin IgG antibody (part of the kit) was added to each well and incubated at $37^{\circ} \mathrm{C}$ for $60 \mathrm{~min}$. Following further washing with PBST, horseradish peroxidase-conjugated pretitrated avidin was added to each well and incubated at $37^{\circ} \mathrm{C}$ for $30 \mathrm{~min}$. After final washing with PBST, the substrate solution was added to each well and allowed to react at $37^{\circ} \mathrm{C}$ for $15 \mathrm{~min}$. The reaction was stopped by the addition of the termination solution, after which the optical density values at $450 \mathrm{~nm}$ were read with an ELISA plate reader. The detection limit of the assay was $4 \mathrm{pg} / \mathrm{ml}$.

Statistical analysis. Experiments were repeated three times. Results are presented as the mean \pm standard deviation. SPSS 17 software (SPSS Inc., Chicago, IL, USA) was used to perform statistical analysis. Statistically significant differences between the means were assessed using one-way analysis of variance. The differences between multiple groups were determined by Tukey's post hoc test and an unpaired Student's t-test was used for the comparison of two groups. $\mathrm{P} \leq 0.01$ was considered to indicate a statistically significant difference.

\section{Results}

AIF-1 expression is upregulated in the mouse model of RIF. UUO, a classic experimental model of progressive RIF (11), was conducted in the present study. Histopathological changes of the kidney sections were evaluated by Masson's trichrome. The results revealed interstitial fibrosis characterized by interstitial collagen deposition and tubular cell atrophy at 14 days after UUO. Compared with the experimental UUO group, SPI treatment reduced the renal tubulointerstitial fibrosis. Interstitial edema and inflammation were also observed in the UUO and SPI group (Fig. 1). Furthermore, $\alpha$-SMA positivity was examined as a marker of activated myofibroblasts involved in ECM production. Immunohistochemical analysis revealed an evidently increased expression of $\alpha$-SMA in the renal interstitium of UUO mice. Compared with the experimental group, the $\alpha$-SMA expression decreased with SPI treatment (Fig. 2A). As assessed by RT-qPCR, $\alpha$-SMA mRNA expression levels in UUO mice were also significantly increased compared with those in sham surgery kidneys. The $\alpha$-SMA expression of the SPI group was significantly decreased compared with the experimental group (Fig. 2B).

To evaluate the role of AIF-1 in promoting RIF,AIF-1 expression in kidney tissues was analyzed. Immunohistochemical results demonstrated that AIF-1 expression was minimal in the normal renal interstitium and notably increased subsequent to UUO. AIF-1 expression of SPI group decreased compared with the experimental group (Fig. 2A). This increase in AIF-1 expression was further confirmed by RT-qPCR, while the expression of AIF-1 was reduced following SPI treatment (Fig. 2B). These results demonstrated that $\alpha$-SMA and AIF-1 expression in kidney tissue were upregulated in the mouse model of progressive RIF. $\alpha$-SMA reflects the degree of renal interstitial fibrosis. AIF-1 may cause the change of $\alpha$-SMA expression and participate in the development of RIF.

AIF-1 is localized in the macrophages infiltrating in the renal interstitium of UUO mice. A previous study has suggested that macrophages that underwent recruitment and infiltration subsequent to injury served a vital role in the development of renal fibrosis (14). The expression of CD68, a macrophage surface marker, was examined in the present study. Compared with the control group, an increased number of CD68-positive cells were observed in the renal interstitium of the UUO group (Fig. 3A). The results revealed that interstitial macrophage infiltration was increased in the UUO kidney, and this was inhibited by SPI treatment. Although AIF-1 expression has been reported to be immunolocalized in podocytes of the glomerular capillary wall in an anti-glomerular basement membrane nephritis model (42), its localization in renal tubulointerstitial injury has not been reported. To detect whether AIF-1 was localized in the interstitial infiltrating macrophages, co-immunofluorescence staining with anti-AIF-1 and anti-CD68 antibodies was performed (Fig. 3B). In kidney sections of UUO mice, the immunoreactivity for AIF-1 was detected on the same cells that were positive for CD68, indicating that AIF-1 protein was localized in macrophages infiltrating the renal interstitium.

AIF-1 expression and secretion by macrophages are upregulated with aldosterone stimulation. AIF-1 expression in macrophages can be induced by inflammatory cytokines, as has been described previously (43); however, induction by aldosterone has not been reported. Physiological concentration of aldosterone increases the expression of proinflammatory genes in cultured macrophages (44). The present study investigated whether aldosterone is capable of inducing AIF-1 expression 

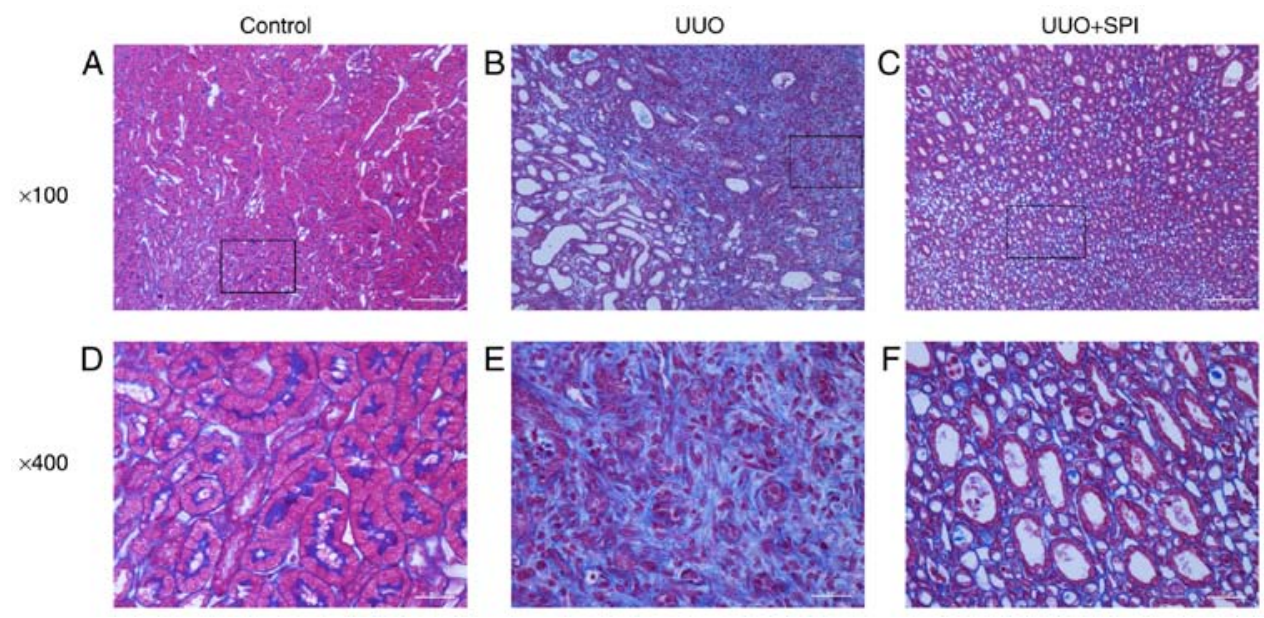

Figure 1. Masson trichrome staining of renal cortex sections from the (A) control, (B) experimental (UUO) and (C) SPI groups at magnification of x100 (scale bar, $50 \mu \mathrm{m}$ ). Stained sections of the (D) control, (E) experimental (UUO) and (F) SPI groups are also shown at magnification of x400 (scale bar, $10 \mu \mathrm{m}$ ). Interstitial collagen deposition (blue) and fibrosis were increased in the obstructive kidney in comparison with the sham surgery kidney. SPI treatment reduced renal interstitial fibrosis compared with that observed in UUO mice. UUO, unilateral ureteric obstruction; SPI, spironolactone.
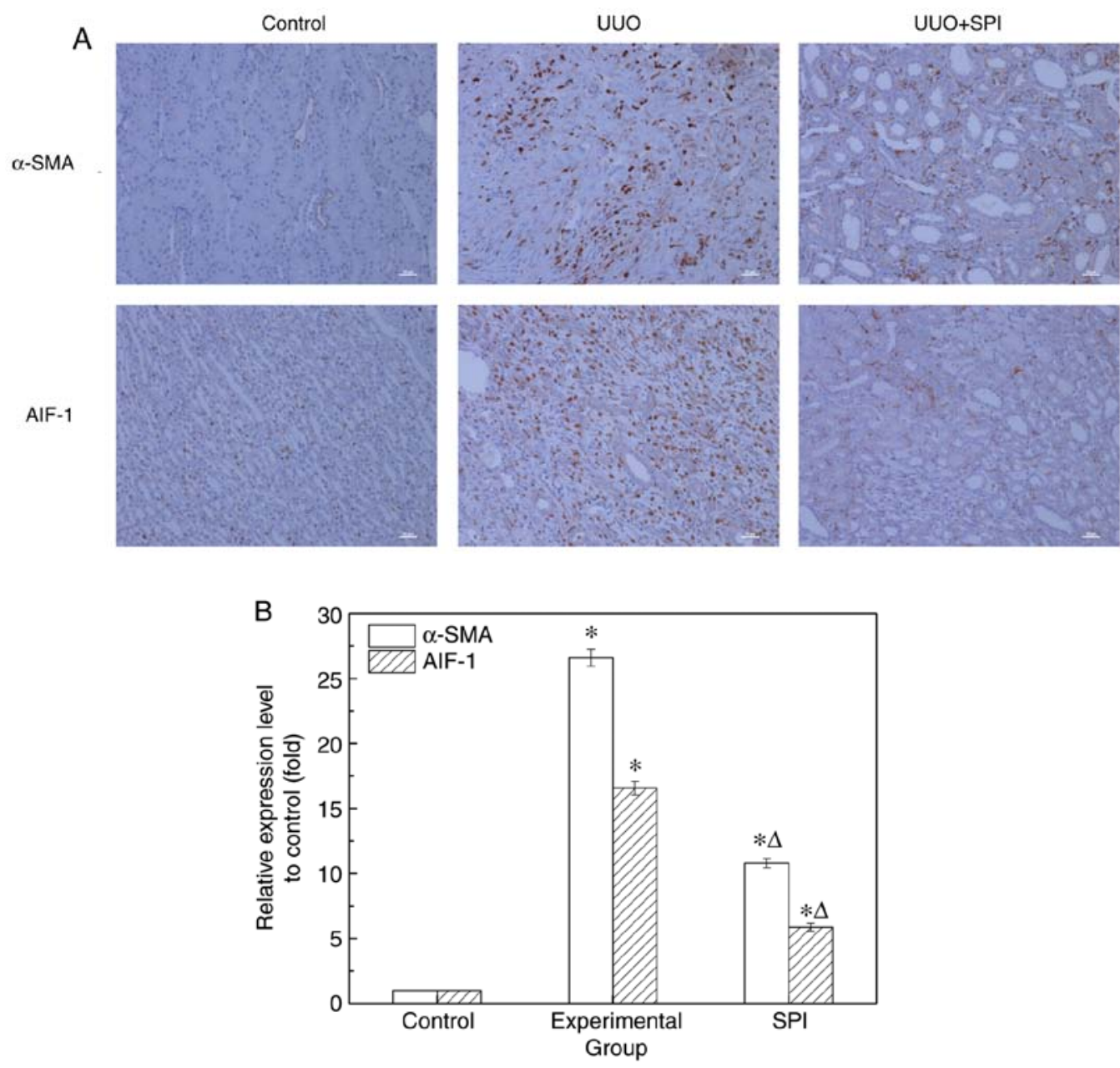

Figure 2. Expression levels of $\alpha$-SMA and AIF-1 were upregulated in a mouse model of progressive renal fibrosis (UUO) and inhibited by SPI treatment. (A) Stained tissues showing $\alpha$-SMA and AIF-1 expression in tubular epithelium in the kidneys of sham surgery mice, UUO days at 14 days after surgery and UUO mice treated with SPI (original magnification, x200; scale bar, $10 \mu \mathrm{m}$ ). (B) Analysis of $\alpha$-SMA and AIF-1 mRNA levels in different groups by reverse transcription-quantitative polymerase chain reaction. ${ }^{\mathrm{P}}<0.01$ vs. control group; ${ }^{\wedge} \mathrm{P} \leq 0.01$ vs. experimental group. UUO, unilateral ureteric obstruction; SPI, spironolactone; $\alpha$-SMA, smooth muscle actin; AIF-1, allograft inflammatory factor-1.

in macrophages. RAW264.7 cells, a commonly used macrophage cell line, were stimulated with different concentrations of aldosterone $\left(10^{-8}-10^{-5} \mathrm{M}\right)$ for $72 \mathrm{~h}$. Following incubation with aldosterone, the protein and mRNA transcription levels 

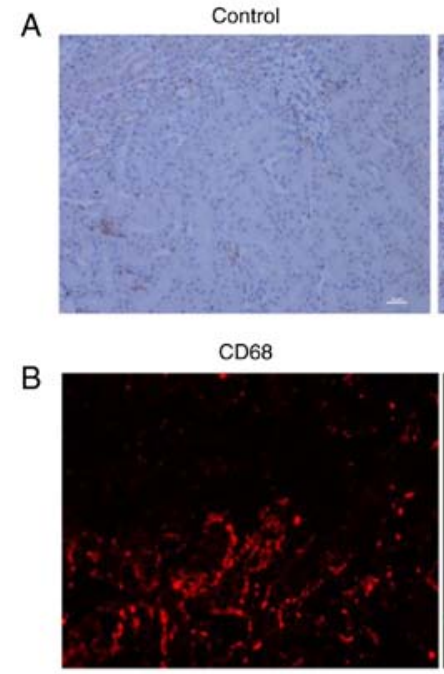

UUO

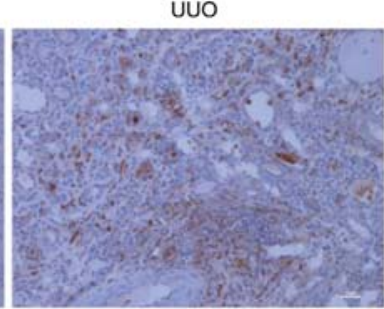

AIF-1

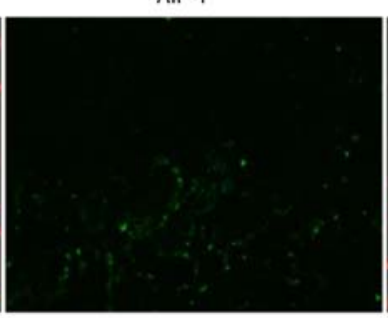

UUO+SPI

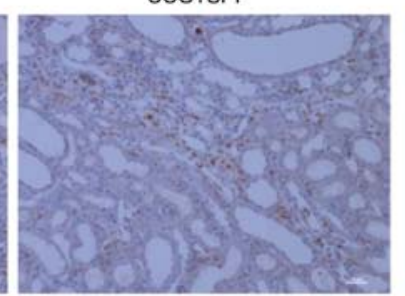

Merge

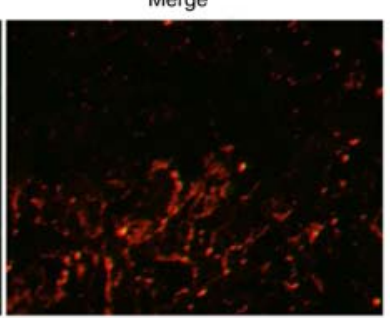

Figure 3. AIF-1 is localized in the macrophages infiltrating in the renal interstitium of UUO mice. (A) The expression of CD68, a macrophage surface marker, was detected by immunohistochemical stain in kidney tissue. Compared with the control group, more CD68-positive cells infiltrating the renal interstitium of the UUO group were detected, which decreased by SPI treatment (original magnification, x200; scale bar, $10 \mu \mathrm{m}$ ). (B) Co-localization of AIF-1 and CD68 in kidney tissue of UUO mice was detected by immunofluorescence staining with anti-AIF-1 antibody (green) and anti-CD68 antibody for macrophages (red), and merging of AIF-1 and CD68 images. UUO, unilateral ureteric obstruction; SPI, spironolactone; AIF-1, allograft inflammatory factor-1.

of AIF-1 in macrophages were upregulated, and the maximum effect occurred at the concentration of $10^{-6} \mathrm{M}$ (Fig. 4A). AIF-1 induction at different time-points was also detected through the treatment of macrophages with aldosterone $\left(10^{-6} \mathrm{M}\right)$ for $6,24,72$ and $120 \mathrm{~h}$. In response to aldosterone stimulation, the mRNA transcription level of AIF-1 was significantly increased and reached a peak value at $72 \mathrm{~h}$, with a 5-fold increase above the basal level, which was also confirmed in the protein level of AIF-1 detected by western blot analysis (Fig. 4B). ELISA was conducted to examine AIF-1 excretion in the supernatant of RAW264.7 cells, and it demonstrated similar results (Fig. 4C and D). Meanwhile, AIF-1 in renal fibroblast cells was also detected. AIF-1 exhibited low expression or secretion by BHK-21 cells with or without aldosterone stimulation.

AIF-1-positive macrophages promote renal fibroblast activation to a profibrotic phenotype. To test the role of AIF-1 in promoting RIF, AIF-1 expression in macrophages was inhibited by stable transfection with siRNA/AIF-1 vector. The macrophage cell line RAW264.7 was selected since it constitutively expresses low levels of AIF-1 mRNA and facilitates positive selection of stable transfectants for AIF-1 gene knockdown (45). The AIF-1 siRNA construct was cloned into the pShuttle vector and stable transfectants were isolated by antibiotic selection. AIF-1 expression was determined using western blot analysis and RT-qPCR. It was demonstrated that stable transfection with the siRNA/AIF-1 construct reduced AIF-1 expression, whereas transfection with vector alone (pShuttle) did not have an evident effect on AIF-1 expression (Fig. 5).

Recent findings have identified that activated renal fibroblasts were the main origin of myofibroblasts, a primary source of ECM in scar tissue formation causing RIF. It has been demonstrated that co-culture of activated immune cells with fibroblasts in vitro induced the production of ECM and expression of $\alpha$-SMA $(5,46)$. To verify the hypothesis that AIF-1-positive macrophages may promote renal fibroblast activation to a profibrotic phenotype, a mouse renal fibroblast
BHK-21 cell line was incubated with RAW264.7 cells with aldosterone stimulation. Expression of $\alpha$-SMA, p-p38 and FN in fibroblasts was examined following co-culture with normal macrophages or macrophages transfected with siRNA/AIF-1. The results revealed that, after $72 \mathrm{~h}$ of co-culture of fibroblasts with macrophages activated by aldosterone, AIF-1 expression in macrophages and supernatants was upregulated, compared with that in the co-culture of two cells without aldosterone (Fig. 6A-C). The protein concentration of TGF- $\beta$ in the supernatants of macrophages was also increased following aldosterone stimulation, but was not significantly different compared with the siRNA/AIF-1 macrophages (Fig. 6C). In addition, the $\alpha$-SMA expression was induced in fibroblasts, with significantly increased expression levels of FN and p-p38 also observed. These levels were reduced significantly in fibroblasts co-cultured with siRNA/AIF-1 macrophages, compared with those in AIF-1-positive macrophages (Fig. 6D and E). These data demonstrate that AIF-1 expression or excretion by macrophages is an important mechanism in the promotion of the profibrotic phenotype in renal fibroblasts, which may occur via the $\mathrm{p} 38$ signaling pathway.

\section{Discussion}

In the present study, the potential link of AIF-1 expression in macrophages with the promotion of RIF was examined. The results demonstrated that AIF-1 expression was upregulated in the animal model of RIF (UUO), and that it was co-localized with CD68-positive macrophages infiltrating in the renal interstitium of UUO mice. In addition, AIF-1 was detected at low levels in unstimulated macrophages, and upregulated in response to aldosterone treatment. The peak expression of AIF-1 was observed at $72 \mathrm{~h}$ after aldosterone $\left(10^{-6} \mathrm{M}\right)$ stimulation. Furthermore, $\alpha$-SMA, p-p38, and FN expression levels in renal fibroblasts were markedly increased following co-culture with macrophages activated by aldosterone. Finally, inhibition of AIF-1 in macrophages transfected with siRNA/AIF-1 
A

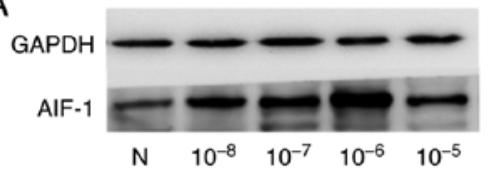

$\mathrm{B}$

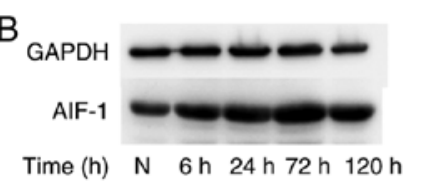

Time (h) $\mathrm{N} 6 \mathrm{~h} 24 \mathrm{~h} 72 \mathrm{~h} 120 \mathrm{~h}$
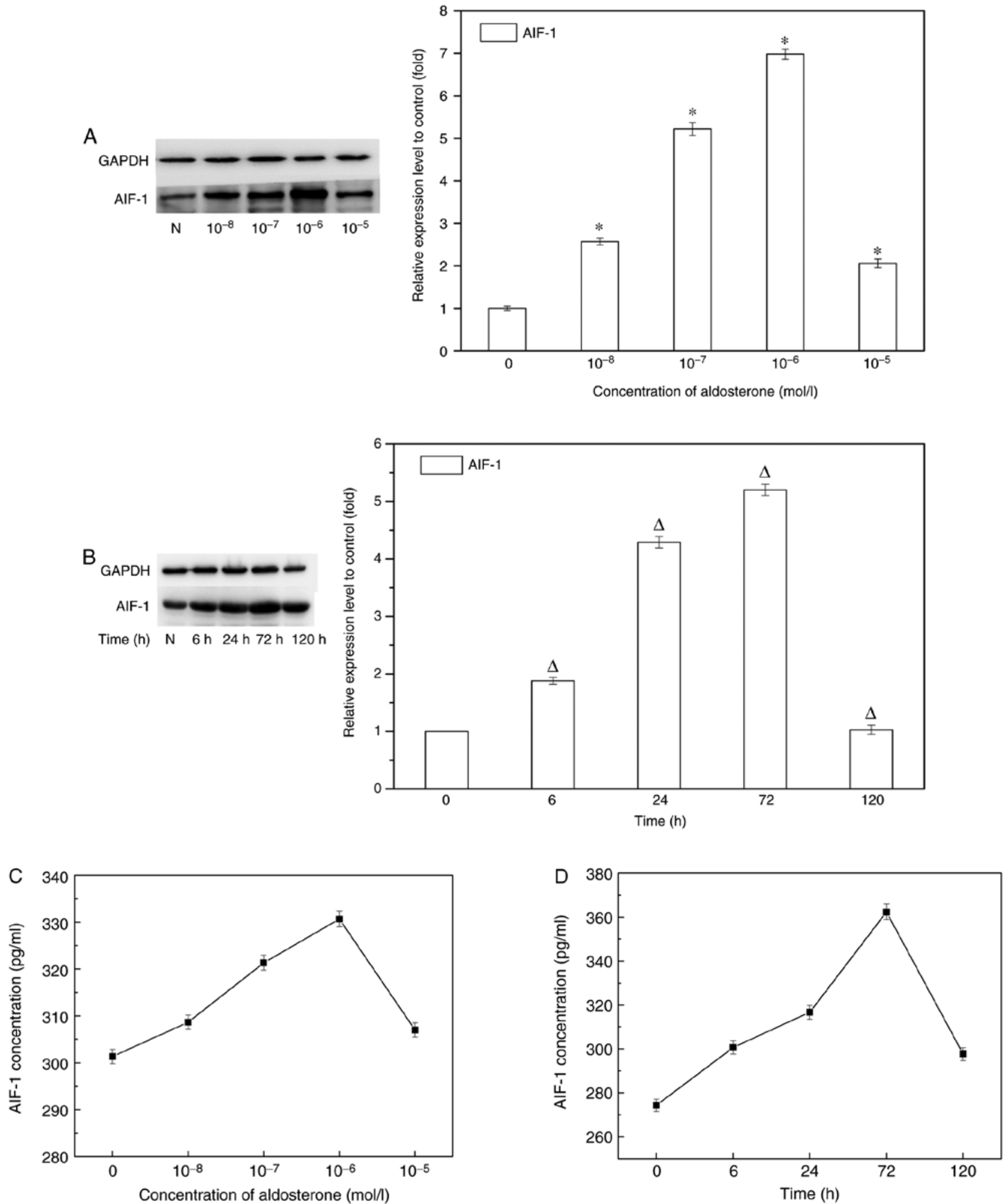

Figure 4. Expression and excretion of AIF-1 in macrophages are upregulated following incubation with aldosterone in vitro. Following stimulation with (A) different concentrations of aldosterone and (B) 10-6 M aldosterone for different incubation times, the protein (left panel) and mRNA (right panel) levels of AIF-1 in macrophages were evaluated by western blot analysis and reverse transcription-quantitative polymerase chain reaction, respectively. Compared with $0,{ }^{*} \mathrm{P} \leq 0.01$ and ${ }^{\Delta} \mathrm{P} \leq 0.01$, vs. $0 \mathrm{~mol} / 1$ aldosterone. Excretion of AIF-1 in macrophages supernatants was also examined by ELISA following treatment with (C) different concentrations of aldosterone and (D) aldosterone for different incubation times. AIF-1, allograft inflammatory factor-1.

reduced the expression levels of profibrotic molecules and p-p38 in fibroblasts. These novel findings demonstrate that AIF-1 expression in macrophages promotes renal fibroblast activation to a profibrotic phenotype and participates in the progression of RIF induced by aldosterone.
As an inflammation-associated protein, AIF-1 has been identified as an important regulator in various inflammatory pathological processes in multiple organs (24). However, there are few studies investigating the function of AIF-1 in kidney diseases, particularly in RIF. A previous study reported that 

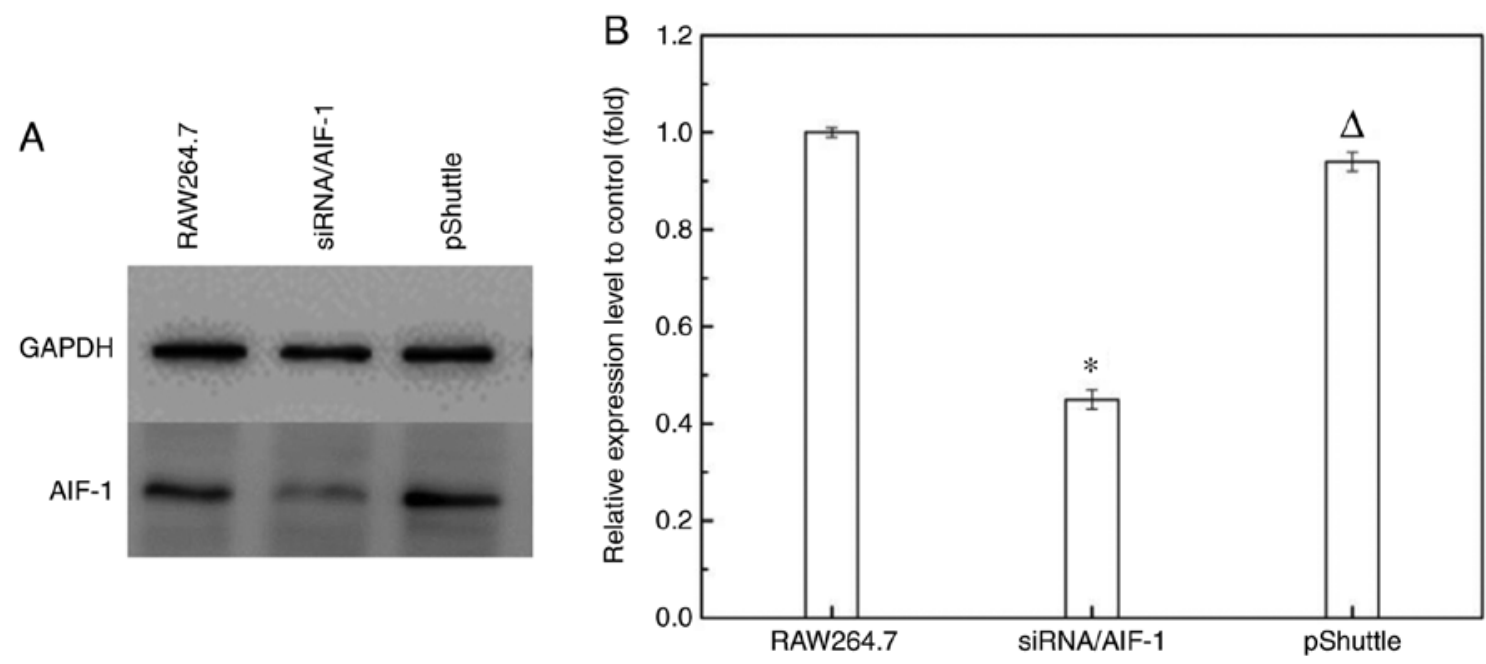

Figure 5. AIF-1 expression in macrophage was determined by (A) western blot analysis and (B) reverse transcription-quantitative polymerase chain reaction following stable transfection with the siRNA/AIF-1 vector. Compared with the control (RAW264.7 only) and pShuttle (vector alone), AIF-1 was knocked down by

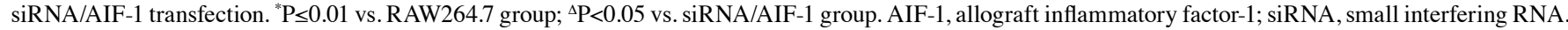

AIF-1-activated macrophages were increased in the infiltrate of clinical rejection biopsies and were associated with clinical rejection episodes, which was the first report on AIF-1 expression in kidney tissue (47). Subsequent studies have demonstrated that AIF-1 involved in the inflammatory signaling network regulated the innate immune responses (48), while the genetic variant TT/CT of the AIF-1 gene was associated with a lower risk of renal rejection (49). Previous studies also indicated that AIF-1 expressed in podocytes and infiltrating inflammatory cells of kidney tissues (42) was associated with inflammatory reaction, immune regulation and allograft rejection $(48,50)$. The results of the present study revealed that AIF-1 expression and infiltration of macrophages occurred in a progressive renal fibrosis model. In accordance with a previous study (42), AIF-1 expression was localized in infiltrating interstitial macrophages of the kidney. Furthermore, as renal fibrosis progresses (collagen accumulation and $\alpha$-SMA expression upregulation), a continued increase in AIF-1 expression was reported in the current study, which demonstrates that AIF-1 participates in the progression of RIF. To the best of our knowledge, this is the first link reported between AIF-1 expression and RIF.

Macrophages are found in normal kidneys and increased numbers are observed in diseased kidney, where they are key players in renal injury, inflammation and fibrosis. Investigation of of experimental and human renal disease has demonstrated that the involvement of macrophages in renal fibrosis results from diverse disease processes. A recent study has explored the nature of both circulating monocytes and tissue macrophages, exhibiting distinct phenotypic and functional characteristics in response to various stimuli in renal fibrosis (51). There are also studies suggesting that there is a subpopulation of macrophages with an antifibrotic role in the UUO model $(52,53)$, although infiltrating macrophages promoting renal fibrosis have been confirmed by one study (54). The macrophage phenotype is altered in response to signals from the local kidney milieu; however, the mechanisms by which macrophages are polarized are not well understood. Macrophage migration and phenotype transitions can be mediated by kidney injury molecule-1 (55). In addition, macrophages overexpressing neutrophil gelatinase-associated lipocalin-2 ameliorated renal inflammation and fibrosis in a UUO mouse model (56). These previous observations indicated that certain factors affect the change of macrophages to different phenotypes. The role and regulated mechanism of macrophages in renal fibrosis are complex and need to be extensively explored. The results of the present study demonstrated that the major tissue source of AIF-1 driving RIF is derived from infiltrating macrophages. Macrophages with distinct phenotypes have a different influence on kidney injury or repair process through the secretion of various cytokines. M1 macrophages produce proinflammatory cytokines, including tumor necrosis factor $\alpha$, interleukin (IL)- 6 and inducible isoform nitric oxide synthase, whereas M2 macrophages can synthesize profibrotic factors, such as TGF- $\beta$, platelet-derived growth factor and galectin-3 $(9,51,57)$. TGF- $\beta$ is a pleiotropic cytokine with multiple effects on cellular behavior, including proliferation, migration and immune response. Aberrant TGF- $\beta$ signaling is considered as a hallmark of certain diseases. Three isoforms of TGF- $\beta$ exist, including TGF- $\beta 1$, TGF- $\beta 2$ and TGF- $\beta 3$, and targeting TGF- $\beta 3$ represents a promising strategy interfering with aberrant TGF- $\beta$ signaling in glioblastoma (58). TGF- $\beta$ has also been implicated as an important mediator of renal fibrosis (59), and thus, the concentration of TGF- $\beta$ was detected in the current study. Following inhibition of the expression of AIF-1 by gene knockdown, the secretion of TGF- $\beta$ in the supernatant of macrophages was not altered as compared with that in the control group. This indicates that AIF-1 promotes renal fibrosis via a TGF- $\beta$-independent signaling pathway, which may provide a new mechanism of macrophages linked with fibrosis and a theoretical foundation to clarify the role of AIF-1 in kidney disease.

Through macrophage co-culture with renal fibroblasts in vitro, the mechanism of the promotion of AIF-1 expression to RIF was further investigated in the current study. Fibroblasts are quiescent cells in the interstitial space of the kidney, which can be activated by inflammatory cells and cytokines. It is considered that $\alpha$-SMA expression of fibroblasts is indicative of myofibroblasts contributing to the pathogenesis of RIF (5). 
A

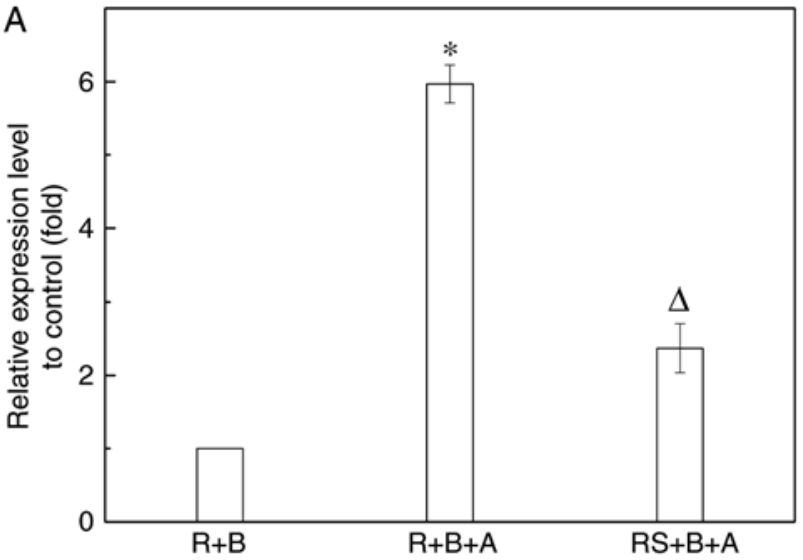

B
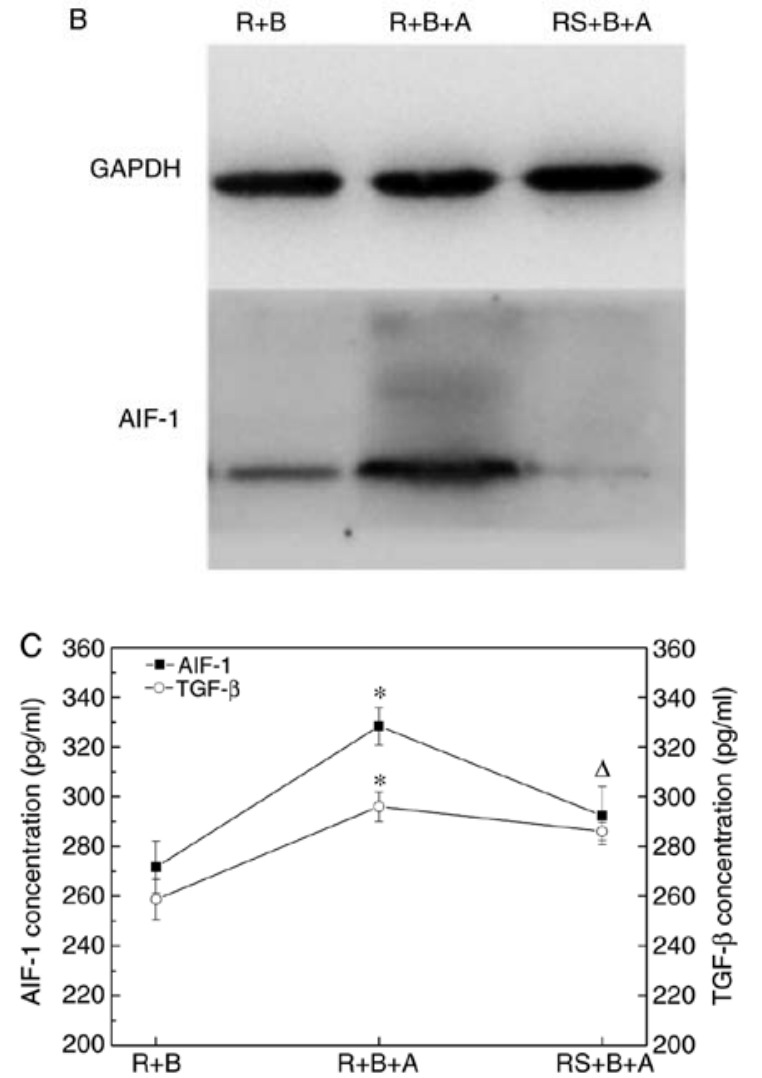

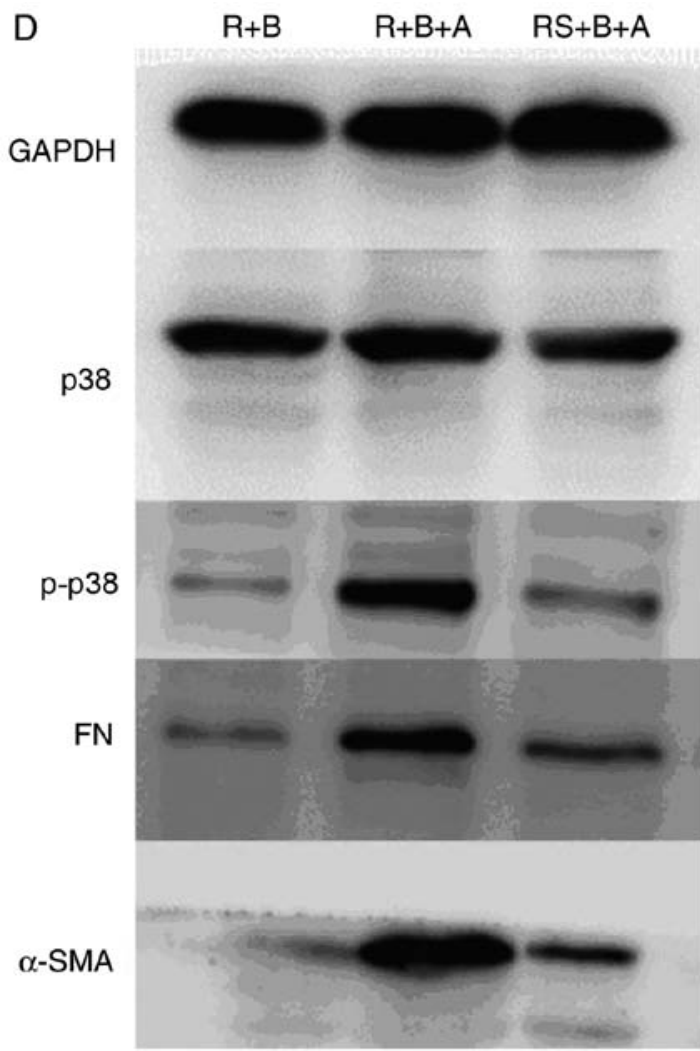

$\mathrm{E}$

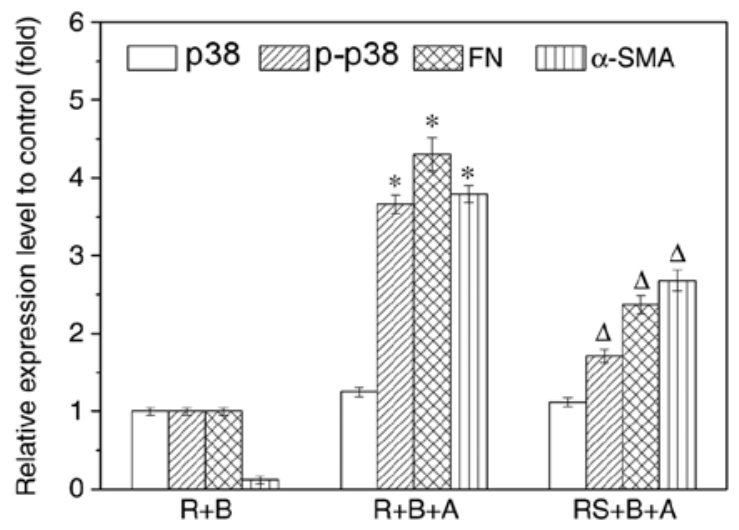

Figure 6. Fibroblasts were activated to a profibrotic phenotype following co-culture with macrophages induced by aldosterone. This phenotypic transition was inhibited by AIF-1 knockdown through transfection with siRNA/AIF-1. Macrophages and renal fibroblasts were separated after incubation for 72 h, and the (A) mRNA and (B) protein expression levels of AIF-1 in macrophages were examined. (C) Secretions of AIF-1 and TGF- $\beta$ in the supernatants of macrophages were also detected. The expression levels of protein kinase (p38 and p-p38), FN and $\alpha$-SMA in fibroblasts were evaluated by (D) western blot analysis and (E) reverse transcription-quantitative polymerase chain reaction. Following co-culture, BHK-21 and RAW264.7 cells were separated and used for further detection. ${ }^{*} \mathrm{P} \leq 0.01$ vs. $\mathrm{R}+\mathrm{B}$ group; ${ }^{\mathrm{P}} \mathrm{P} \leq 0.01$ vs. $\mathrm{R}+\mathrm{B}+\mathrm{A}$ group. $\mathrm{R}, \mathrm{RAW} 264.7$ cells (macrophages); B, BHK-21 cells (renal fibroblasts); A, aldosterone stimulation; RS, RAW264.7 cells transfected with siRNA/AIF-1; AIF-1, allograft inflammatory factor-1; siRNA, small interfering RNA; p-p38, phosphorylated p38; FN, fibronectin; $\alpha$-SMA, smooth muscle actin.

However, further investigation is required to elucidate the cellular mechanisms underlying the renal fibroblast transition to myofibroblasts. It has been reported that AIF-1, which can induce the migration of fibroblasts, and the production of IL-6, is an important molecule promoting fibrosis in chronic graft versus host disease (60). Therefore, the present study hypothesize that AIF-1 participates in the mechanism of renal fibroblast transition to myofibroblasts. The results demonstrated that upregulation of AIF-1 in active macrophages served a key role in promoting FN and $\alpha$-SMA expression levels in fibroblasts.
Furthermore, AIF-1 has been reported to be associated with fibrosis-associated diseases. A previous study indicated that AIF-1 played an important role in the pathogenesis of systemic sclerosis (61). AIF-1 also promoted tissue $\mathrm{T}$ cell production of cytokines capable of inducing the expression of IL- 6 , TGF- $\beta$ and $\alpha$-SMA in normal dermal fibroblasts, and increasing their collagen production (37). These findings implied that AIF-1 promotes normal fibroblasts to the fibrotic phenotype. Our previous study indicated that the interaction between renal fibroblasts and peripheral blood mononuclear 
cells was mediated through direct cell-to-cell contact involved in renal interstitial inflammation (62). The current study further demonstrated that AIF-1 expression by macrophages induced the activation of normal renal fibroblasts, increasing the expression of fibrosis markers, including FN and $\alpha$-SMA, in these cells, and this effect may direct cell-to-cell contact between macrophages and renal fibroblasts.

AIF-1 participates in signaling cascades in macrophages, vascular smooth muscle cells and endothelial cells (ECs). The absence of AIF-1 leads to the activation of suppressed kinases, which interrupts the signaling cascades. However, the AIF-1 mediated signal transduction pathway involves different types of cells. In macrophages, AIF-1 attenuation reduced the activation of p38/MAPK, AKT and p90RSK kinases (30). In murine vascular smooth muscle cells, overexpression of AIF-1 increased p38 activation (63). However, a study on ECs reported that abrogation or overexpression of AIF-1 does not alter p38/MAPK activation, while the reduction of AIF-1 expression significantly inhibited the activation of p44/42 in ECs (64). As a classic signaling pathway participating in a variety of reactions, p38/MAPK is used as a target to downstream alterations in the pathophysiological process. A study revealed that microRNA mimics targeting p38/MAPK signaling pathway inhibited broad-spectrum respiratory virus infection (65). Inhibition of p38/MAPK also attenuated $\mathrm{Hg}$-induced $\mathrm{FN}$ of renal interstitial fibroblasts and renal fibrosis in mice $(66,67)$. Due to the upregulation of fibroblast activation and renal interstitial fibrosis induced by AIF-1, the present study focused on p38 kinase and observed that reduction of AIF-1 expression significantly inhibited the activation of p38/MAPK. This suggests that decreased profibrotic phenotype transformation in fibroblasts with AIF-1 abrogation may be attributed to the reduction of p38/MAPK activation.

Aldosterone and activation of the mineralocorticoid receptor (MR) serve a key role in macrophages, and cause tubulointerstitial fibrosis and glomerular injury in the kidney (68). Aldosterone at a physiological concentration increases the expression of pro-inflammatory genes in cultured macrophages. In addition, aldosterone receptor blocker suppresses the release of interstitial inflammatory cytokines from macrophages, which may serve to delay the progression of renal fibrosis. Aldosterone also induces the activation of macrophage, while MR controls macrophage polarization $(44,69)$. As an inflammation-associated protein in macrophages, AIF-1 is upregulated and promotes RIF with aldosterone stimulation, which was verified in the present study. Aldosterone is known to bind to the cytoplasmic MR, which functions as a transcription factor to regulate gene transcription (70). In addition to this traditional genomic pathway, aldosterone can also exert rapid nongenomic effects that are not blocked by inhibitors of transcription. These rapid actions (requiring seconds to minutes) are coupled to MR or to a specific membrane aldosterone receptor. Systemic aldosterone administration induces phosphorylation of epidermal growth factor receptor and extracellular signal-regulated kinase (ERK) in the kidney within $30 \mathrm{~min}$. Aldosterone rapidly activates ERK1/2 in vascular smooth muscle cells in order to promote a mitogenic and profibrotic phenotype. This mechanism is MR-independent, and certain rapid effects of aldosterone cannot be blocked by SPI, an MR antagonist (38).
In subsequent studies, our study will focus on the definite mechanism of AIF-1 expression regulated by aldosterone and will determine whether it is MR-dependent. AIF-1 expression in macrophages and its regulation effect on proliferation, migration and inflammation has previously been explored (30). However, the function and mechanism of AIF-1 on the development of fibrosis is undefined in previous studies. To the best of our knowledge, the present study is the first to prove that AIF-1 expression in macrophages promotes RIF. Through AIF-1 abrogation by stable transfection with siRNA and co-culture of macrophages with renal fibroblasts, the current study demonstrated the key role of AIF-1 in the renal fibroblast activation to a profibrotic phenotype and in the promotion of RIF. The profibrotic signaling axis between macrophages and renal fibroblasts was mediated by AIF-1. Therefore, targeted inhibition of AIF-1 expression in macrophages may result in the development of novel antifibrotic therapies. Renal fibroblasts are the main inherent cells with an important role in promoting RIF (5). Given that the functional consequences of AIF-1 expression in fibroblasts have been reported (71), there is the implication that the association between AIF-1 and renal fibrosis is complex and the exact mechanism requires further investigation.

In conclusion, the present study illustrated that upregulation of AIF-1 expression and secretion by macrophage stimulated with aldosterone promoted renal fibroblast to a profibrotic phenotype. This is a novel mechanism linking macrophages to the promotion of RIF, which may occur via the p38 signaling pathway.

\section{Acknowledgements}

The authors would like to thank Mrs Cailing Guo (Microbiology Department of Harbin Medical University, Harbin, China) and Miss Yiqun Ren (Pathology Laboratory of the Nephrology Department, The First Affiliated Hospital of Harbin Medical University, Harbin, China) for their technical assistance.

\section{Funding}

The present study was supported by the National Natural Science Foundation of China (grant no. 81570638) and the Scientific Funding Project for the Returned Overseas of Education Department of Heilong Jiang Province (grant no. 1253HQ006).

\section{Availability of data and materials}

All data generated or analyzed during this study are included in this published article.

\section{Authors' contributions}

$\mathrm{XW}$ was a major contributor in experimental design. LZ established the animal models. XY performed the protein test. $\mathrm{JH}$ participated in cell culture. JN guided the writing of the manuscript. All authors read and approved the final manuscript.

\section{Ethics approval and consent to participate}

All experimental procedures adhered to the principles stated in the Guide for the Care and Use of Laboratory Animals 
(updated 2011; National Institutes of Health, Bethesda, MD, USA) and were approved by the Experimental Animal Usage and Welfare Ethics Committee of Harbin Medical University (Harbin, China).

\section{Consent for publication}

Not applicable.

\section{Competing interests}

The authors declare that they have no competing interests.

\section{References}

1. Farris AB and Colvin RB: Renal interstitial fibrosis: Mechanisms and evaluation. Curr Opin Nephrol Hypertens 21: 289-300, 2012

2. Zeisberg M and Neilson EG: Mechanisms of tubulointerstitial fibrosis. J Am Soc Nephrol 21: 1819-1834, 2010.

3. Duffield JS: Cellular and molecular mechanisms in kidney fibrosis. J Clin Invest 124: 2299-2306, 2014.

4. Strutz F and Zeisberg M: Renal fibroblasts and myofibroblasts in chronic kidney disease. J Am Soc Nephrol 17: 2992-2998, 2006

5. Sun YB, Qu X, Caruana G and Li J: The origin of renal fibroblasts/myofibroblasts and the signals that trigger fibrosis Differentiation 92: 102-107, 2016.

6. Asada N, Takase M, Nakamura J, Oguchi A, Asada M, Suzuki N, Yamamura K, Nagoshi N, Shibata S, Rao TN, et al: Dysfunction of fibroblasts of extrarenal origin underlies renal fibrosis and renal anemia in mice. J Clin Invest 121: 3981-3990, 2011.

7. Li X and Zhuang S: Recent advances in renal interstitial fibrosis and tubular atrophy after kidney transplantation. Fibrogenesis Tissue Repair 7: 15, 2014

8. Han HI, Skvarca LB, Espiritu EB, Davidson AJ and Hukriede NA The role of macrophages during acute kidney injury: Destruction and repair. Pediatr Nephrol, 2018.

9. Cao Q, Harris DC and Wang Y: Macrophages in kidney injury, inflammation, and fibrosis. Physiology (Bethesda) 30: 183-194, 2015.

10. Yonemoto S, Machiguchi T, Nomura K, Minakata T, Nanno M and Yoshida H: Correlations of tissue macrophages and cytoskeletal protein expression with renal fibrosis in patients with diabetes mellitus. Clin Exp Nephrol 10: 186-192, 2006.

11. Chevalier RL, Forbes MS and Thornhill BA: Ureteral obstruction as a model of renal interstitial fibrosis and obstructive nephropathy. Kidney Int 75: 1145-1152, 2009

12. Wang M, Liu R, Jia X, Mu S and Xie R: N-acetyl-seryl-aspartyllysyl-proline attenuates renal inflammation and tubulointerstitial fibrosis in rats. Int J Mol Med 26: 795-801, 2010.

13. Diamond JR: Macrophages and progressive renal disease in experimental hydronephrosis. Am J Kidney Dis 26: 133-140, 1995.

14. Kitamoto K, Machida Y, Uchida J, Izumi Y, Shiota M, Nakao T, Iwao H, Yukimura T, Nakatani $T$ and Miura K: Effects of liposome clodronate on renal leukocyte populations and renal fibrosis in murine obstructive nephropathy. J Pharmacol Sci 111: 285-292, 2009.

15. Eis V, Luckow B, Vielhauer V, Siveke JT, Linde Y, Segerer S, Perez De Lema G, Cohen CD, Kretzler M, Mack M, et al: Chemokine receptor CCR1 but not CCR5 mediates leukocyte recruitment and subsequent renal fibrosis after unilateral ureteral obstruction. J Am Soc Nephrol 15: 337-347, 2004

16. Kitagawa K, Wada T, Furuichi K, Hashimoto H, Ishiwata Y, Asano M, Takeya M, Kuziel WA, Matsushima K, Mukaida N and Yokoyama H: Blockade of CCR2 ameliorates progressive fibrosis in kidney. Am J Pathol 165: 237-246, 2004.

17. MacKinnon AC, Farnworth SL, Hodkinson PS, Henderson NC Atkinson KM, Leffler H, Nilsson UJ, Haslett C, Forbes SJ and Sethi T: Regulation of alternative macrophage activation by galectin-3. J Immunol 180: 2650-2658, 2008

18. Henderson NC, Mackinnon AC, Farnworth SL, Kipari T, Haslett C, Iredale JP, Liu FT, Hughes J and Sethi T: Galectin-3 expression and secretion links macrophages to the promotion of renal fibrosis. Am J Pathol 172: 288-298, 2008.
19. Hugo $\mathrm{C}$ and Daniel $\mathrm{C}$ : Thrombospondin in renal disease. Nephron Exp Nephrol 111: e61-e66, 2009.

20. Wynes MW, Frankel SK and Riches DW: IL-4-induced macrophage-derived IGF-I protects myofibroblasts from apoptosis following growth factor withdrawal. J Leukoc Biol 76 1019-1027, 2004

21. Lin SL, Kisseleva T, Brenner D A and Duffield JS: Pericytes and perivascular fibroblasts are the primary source of collagen-producing cells in obstructive fibrosis of the kidney. Am J Pathol 173: 1617-1627, 2008.

22. Mori R, Shaw TJ and Martin P: Molecular mechanisms linking wound inflammation and fibrosis: Knockdown of osteopontin leads to rapid repair and reduced scarring. J Exp Med 205: 43-51, 2008.

23. Chujo S, Shirasaki F, Kondo-Miyazaki M, Ikawa Y and Takehara K: Role of connective tissue growth factor and its interaction with basic fibroblast growth factor and macrophage chemoattractant protein-1 in skin fibrosis. J Cell Physiol 220 189-195, 2009.

24. Zhao YY, Yan DJ and Chen ZW: Role of AIF-1 in the regulation of inflammatory activation and diverse disease processes. Cell Immunol 284: 75-83, 2013.

25. Utans U, Arceci RJ, Yamashita Y and Russell ME: Cloning and characterization of allograft inflammatory factor-1: A novel macrophage factor identified in rat cardiac allografts with chronic rejection. J Clin Invest 95: 2954-2962, 1995.

26. Utans U, Quist WC, McManus BM, Wilson JE, Arceci RJ, Wallace AF and Russell ME: Allograft inflammatory factory-1. A cytokine-responsive macrophage molecule expressed in transplanted human hearts. Transplantation 61: 1387-1392, 1996.

27. Imai Y, Ibata I, Ito D, Ohsawa K, and Kohsaka S: A novel gene ibal in the major histocompatibility complex class III region encoding an EF hand protein expressed in a monocytic lineage. Biochem Biophys Res Commun 224: 855-862, 1996.

28. Tanaka S, Suzuki K, Watanabe M, Matsuda A, Tone S and Koike T: Upregulation of a new microglial gene, mrf-1, in response to programmed neuronal cell death and degeneration. J Neurosci 18: 6358-6369, 1998.

29. Chen ZW, Ahren B, Ostenson CG, Cintra A, Bergman T, Möller C, Fuxe K, Mutt V, Jörnvall $H$ and Efendic S: Identification, isolation, and characterization of daintain (allograft inflammatory factor 1), a macrophage polypeptide with effects on insulin secretion and abundantly present in the pancreas of prediabetic BB rats. Proc Natl Acad Sci USA 94: 13879-13884, 1997.

30. Tian Y, Kelemen SE and Autieri MV: Inhibition of AIF-1 expression by constitutive siRNA expression reduces macrophage migration, proliferation, and signal transduction initiated by atherogenic stimuli. Am J Physiol Cell Physiol 290: C1083-C1091, 2006.

31. Watano K, Iwabuchi K, Fujii S, Ishimori N, Mitsuhashi S, Ato M, Kitabatake A and Onoé K: Allograft inflammatory factor-1 augments production of interleukin- $6,-10$ and -12 by a mouse macrophage line. Immunology 104: 307-316, 2001.

32. Yang ZF, Ho DW, Lau CK, Lam CT, Lum CT, Poon RT and Fan ST: Allograft inflammatory factor-1 (AIF-1) is crucial for the survival and pro-inflammatory activity of macrophages. Int Immunol 17: 1391-1397, 2005.

33. Kadoya M, Yamamoto A, Hamaguchi M, Obayashi $\mathrm{H}$, Mizushima K, Ohta M, Seno T, Oda R, Fujiwara H, Kohno M and Kawahito Y: Allograft inflammatory factor-1 stimulates chemokine production and induces chemotaxis in human peripheral blood mononuclear cells. Biochem Biophys Res Commun 448: 287-291, 2014.

34. Mishima T, Iwabuchi K, Fujii S, Tanaka SY, Ogura H, Watano-Miyata K, Ishimori N, Andoh Y, Nakai Y, Iwabuchi $\mathrm{C}$, et al: Allograft inflammatory factor-1 augments macrophage phagocytotic activity and accelerates the progression of atherosclerosis in ApoE ${ }^{-/-}$mice. Int J Mol Med 21: 181-187, 2008.

35. Fukui M, Tanaka M, Asano M, Yamazaki M, Hasegawa G, Imai S, Fujinami A, Ohta M, Obayashi $\mathrm{H}$ and Nakamura N: Serum allograft inflammatory factor-1 is a novel marker for diabetic nephropathy. Diabetes Res Clin Pract 97: 146-150, 2012.

36. Chen QR, Guan F, Song SM, Jin JK, Lei DS, Chen CM, Lei JH, Chen ZW and Niu AO: Allograft inflammatory factor-1 alleviates liver disease of BALB/c mice infected with Schistosoma japonicum. Parasitol Res 113: 2629-2639, 2014.

37. Del Galdo F and Jimenez SA: T cells expressing allograft inflammatory factor 1 display increased chemotaxis and induce a profibrotic phenotype in normal fibroblasts in vitro. Arthritis Rheum 56: 3478-3488, 2007. 
38. Brown NJ: Contribution of aldosterone to cardiovascular and renal inflammation and fibrosis. Nat Rev Nephrol 9: 459-469, 2013.

39. Ranjit S, Dvornikov A, Levi M, Furgeson S and Gratton E: Characterizing fibrosis in UUO mice model using multiparametric analysis of phasor distribution from FLIM images. Biomed Opt Express 7: 3519-3530, 2016.

40. Autieri MV, Carbone C and Mu A: Expression of allograft inflammatory factor- 1 is a marker of activated human vascular smooth muscle cells and arterial injury. Arterioscler Thromb Vasc Biol 20: 1737-1744, 2000.

41. Livak KJ and Schmittgen TD: Analysis of relative gene expression data using real-time quantitative PCR and the 2(-Delta Delta C(T)) method. Methods 25: 402-408, 2001

42. Tsubata Y, Sakatsume M, Ogawa A, Alchi B, Kaneko Y, Kuroda T, Kawachi H, Narita I, Yamamoto T and Gejyo F: Expression of allograft inflammatory factor-1 in kidneys: A novel molecular component of podocyte. Kidney Int 70: 1948-1954, 2006.

43. Yamamoto A and Kawahito Y: The immunologic function and role of allograft inflammatory factor-1. Nihon Rinsho Meneki Gakkai Kaishi 37: 139-145, 2014 (In Japanese).

44. Usher MG, Duan SZ, Ivaschenko CY, Frieler RA, Berger S, Schutz G, Lumeng CN and Mortensen RM: Myeloid mineralocorticoid receptor controls macrophage polarization and cardiovascular hypertrophy and remodeling in mice. J Clin Invest 120: 3350-3364, 2010.

45. Sibinga NE, Feinberg MW, Yang H, Werner F and Jain MK: Macrophage-restricted and interferon gamma-inducible expression of the allograft inflammatory factor-1 gene requires Pu.1. J Biol Chem 277: 16202-16210, 2002.

46. Cook HT: The origin of renal fibroblasts and progression of kidney disease. Am J Pathol 176: 22-24, 2010.

47. Grimm PC, McKenna R, Nickerson P, Russell ME, Gough J, Gospodarek E, Liu B, Jeffery J and Rush DN: Clinical rejection is distinguished from subclinical rejection by increased infiltration by a population of activated macrophages. J Am Soc Nephrol 10: $1582-1589,1999$.

48. McDaniel DO, Rigney DA, McDaniel KY, Windham WJ, Redmond P, Williams B, Zhou X, Hawxby A and Butt F: Early expression profile of inflammatory markers and kidney allograft status. Transplant Proc 45: 1520-1523, 2013.

49. Vu D, Tellez-Corrales E, Shah T, Hutchinson I and Min DI: Influence of Cyclooxygenase-2 (COX-2) gene promoter-1195 and allograft inflammatory factor-1 (AIF-1) polymorphisms on allograft outcome in Hispanic kidney transplant recipients. Hum Immunol 74: 1386-1391, 2013.

50. Brauner A, Hertting O, Alkstrand E, Sandberg E, Chromek M, Chen ZW and Ostenson CG: CAPD peritonitis induces the production of a novel peptide, daintain/allograft inflammatory factor-1. Perit Dial Int 23: 5-13, 2003.

51. Meng XM, Tang PM, Li J and Lan HY: Macrophage phenotype in kidney injury and repair. Kidney Dis (Basel) 1: 138-146, 2015.

52. Nishida M, Okumura Y, Fujimoto S, Shiraishi I, Itoi T and Hamaoka K: Adoptive transfer of macrophages ameliorates renal fibrosis in mice. Biochem Biophys Res Commun 332: 11-16, 2005.

53. López-Guisa JM, Cai X, Collins SJ, Yamaguchi I, Okamura DM, Bugge TH, Isacke CM, Emson CL, Turner SM, Shankland SJ, et al: Mannose receptor 2 attenuates renal fibrosis. J Am Soc Nephrol 23: 236-251, 2012.

54. Huen SC and Cantley LG: Macrophages in Renal Injury and Repair. Annu Rev Physiol 79: 449-469, 2017.

55. Tian L, Shao X, Xie Y, Wang Q, Che X, Zhang M, Xu W, $\mathrm{Xu}$ Y, Mou S and Ni Z: Kidney injury molecule-1 is elevated in nephropathy and mediates macrophage activation via the Mapk signalling pathway. Cell Physiol Biochem 41: 769-783, 2017.

56. Guiteras R, Sola A, Flaquer M, Hotter G, Torras J, Grinyó JM and Cruzado JM: Macrophage overexpressing NGAL ameliorated kidney fibrosis in the UUO mice model. Cell Physiol Biochem 42: 1945-1960, 2017.
57. Xu Y, Yang S, Huang J, Ruan S, Zheng Z and Lin J: Tgf- $\beta 1$ induces autophagy and promotes apoptosis in renal tubular epithelial cells. Int J Mol Med 29: 781-790, 2012.

58. Seystahl K, Papachristodoulou A, Burghardt I, Schneider H, Hasenbach K, Janicot M, Roth P and Weller M: Biological role and therapeutic targeting of TGF- $\beta_{3}$ in glioblastoma. Mol Cancer Ther 16: 1177-1186, 2017.

59. Vega G, Alarcon S and San Martín R: The cellular and signalling alterations conducted by TGF- $\beta$ contributing to renal fibrosis. Cytokine 88: 115-125, 2016

60. Yamamoto A, Ashihara E, Nakagawa Y, Obayashi H, Ohta M, Hara H, Adachi T, Seno T, Kadoya M, Hamaguchi M, et al: Allograft inflammatory factor-1 is overexpressed and induces fibroblast chemotaxis in the skin of sclerodermatous GVHD in a murine model. Immunol Lett 135: 144-150, 2011.

61. Del Galdo F, Maul GG, Jiménez SA and Artlett CM: Expression of allograft inflammatory factor 1 in tissues from patients with systemic sclerosis and in vitro differential expression of its isoforms in response to transforming growth factor beta. Arthritis Rheum 54: 2616-2625, 2006

62. Hao L, Okada H, Kanno Y, Inoue T, Kobayashi T, Watanabe Y, Strutz F, Müller GA and Suzuki H: Direct contact between human peripheral blood mononuclear cells and renal fibroblasts facilitates the expression of monocyte chemoattractant protein-1. Am J Nephrol 23: 208-213, 2003

63. Sommerville LJ, Kelemen SE and Autieri MV: Increased smooth muscle cell activation and neointima formation in response to injury in AIF-1 transgenic mice. Arterioscler Thromb Vasc Biol 28: 47-53, 2008.

64. Tian Y, Jain S, Kelemen SE and Autieri MV: AIF-1 expression regulates endothelial cell activation, signal transduction, and vasculogenesis. Am J Physiol Cell Physiol 296: C256-C266, 2009.

65. McCaskill JL, Ressel S, Alber A, Redford J, Power UF, Schwarze J, Dutia BM and Buck AH: Broad-spectrum inhibition of respiratory virus infection by MicroRNA mimics targeting p38 MAPK signaling. Mol Ther Nucleic Acids 7: 256-266, 2017.

66. Wang D, Warner GM, Yin P, Knudsen BE, Cheng J, Butters KA Lien KR, Gray CE, Garovic VD, Lerman LO, et al: Inhibition of p38 MAPK attenuates renal atrophy and fibrosis in a murine renal artery stenosis model. Am J Physiol Renal Physiol 304: F938-F947, 2013.

67. Huang JS, Chuang CT, Liu MH, Lin SH, Guh JY and Chuang LY: Klotho attenuates high glucose-induced fibronectin and cell hypertrophy via the ERK1/2-p38 kinase signaling pathway in renal interstitial fibroblasts. Mol Cell Endocrinol 390: 45-53, 2014.

68. Blasi ER, Rocha R, Rudolph AE, Blomme EA, Polly ML and McMahon EG: Aldosterone/salt induces renal inflammation and fibrosis in hypertensive rats. Kidney Int 63: 1791-1800, 2003.

69. Kadoya H, Satoh M, Sasaki T, Taniguchi S, Takahashi M and Kashihara N: Excess aldosterone is a critical danger signal for inflammasome activation in the development of renal fibrosis in mice. FASEB J 29: 3899-3910, 2015.

70. Bengough AG, Hans J, Bransby MF and Valentine TA: PIV as a method for quantifying root cell growth and particle displacement in confocal images. Microsc Res Tech 73: 27-36, 2010.

71. Nagahara H, Yamamoto A, Seno T, Obayashi H, Kida T, Nakabayashi A, Kukida Y, Fujioka K, Fujii W, Murakami K, et al: Allograft inflammatory factor-1 in the pathogenesis of bleomycin-induced acute lung injury. Biosci Trends 10: 47-53, 2016.

This work is licensed under a Creative Commons Attribution-NonCommercial-NoDerivatives 4.0 International (CC BY-NC-ND 4.0) License. 